\title{
Comparative Study on Mechanical Properties of Compacted Clay under Freeze-Thaw Cycles with Closed and Open Systems
}

\author{
Shaohua Xian, ${ }^{1,2}$ Zheng Lu $\mathbb{D}^{1},{ }^{1}$ Hailin Yao, ${ }^{1}$ Ran Fang, ${ }^{1,2}$ and Jianbo She ${ }^{1,2}$ \\ ${ }^{1}$ State Key Laboratory of Geomechanics and Geotechnical Engineering, Institute of Rock and Soil Mechanics, \\ Chinese Academy of Sciences, Wuhan 430071, China \\ ${ }^{2}$ University of Chinese Academy of Sciences, Beijing 100049, China
}

Correspondence should be addressed to Zheng Lu; lzwhrsm@163.com

Received 25 January 2019; Accepted 25 March 2019; Published 15 April 2019

Academic Editor: Giorgio Pia

Copyright ( 12019 Shaohua Xian et al. This is an open access article distributed under the Creative Commons Attribution License, which permits unrestricted use, distribution, and reproduction in any medium, provided the original work is properly cited.

\begin{abstract}
The frost heave and thaw settlement caused by freeze-thaw cycles will seriously affect the engineering properties of soil. This paper attempts to comparatively investigate the deterioration effect of freeze-thaw cycles on the mechanical properties of compacted clay in closed and open systems. The specimens were frozen and thawed from the top to bottom in two systems. The moisture contents and deformations after freeze-thaw cycles were measured. Mechanical parameters of soil were examined through triaxial compression tests. Results show that the moisture content and deformation of soil change evidently with the increase of freeze-thaw cycles in the open system, while these parameters in the closed system change little. In the open system, the attenuation rate of failure strength, elastic modulus, and angle of internal friction of soil subjected to 7 freeze-thaw cycles are all about 2 times as large as that in the closed system and the attenuation rate of cohesion is even 4 times of that in the closed system. These differences reveal that the deterioration effect of freeze-thaw cycles on soil strength is aggravated after water supply. These findings indicate that soil structure damage and moisture content increase is the dominant factor affecting engineering properties of the soil in the open system.
\end{abstract}

\section{Introduction}

When the soil completely freezes in situ, the volume of free water in the voids increases by $9 \%$, which is very common in coarse-grained soil, such as sand. For the clayey soil, when the freezing rate is low, especially when there is an external source of water supply, the migration and aggregation of unfrozen water to the frozen front under the driving of cryosuction [1] lead to the formation of the segregated ice, that is, the ice lens, resulting in the frost heave of the soil [2]. Frost heaving causes structural damage to the soil, thus reducing the soil strength [3-5]. After winter season, when the external temperature increases, the ice lens will melt, resulting in the increase of soil moisture and then causing a significant weakening phenomenon in soil $[6,7]$.

The study on the effect of freeze-thaw cycles on the mechanical properties of soil generally adopts two kinds of test methods. The one is the freeze-thaw cycles test in the closed system where no outer water is available during the freezing process, and the other is in the open system where outer water is supplied from the bottom of the sample during the freezing process [8]. Referring to the viewpoint of Wong and Haug [8] that the development rate of frost depth is greater than that of moisture migration in soil, numerous authors have studied the influence of freeze-thaw cycles on the mechanical properties of soil under the closed system [9-12]. The existing investigations have been carried out focusing on the strength properties of the soil after freezethaw cycles, such as the unconfined compressive strength [3], failure strength [11], shear strength [12, 13], and modulus of elasticity $[14,15]$. These previous studies are conducive to deeply understand engineering properties of soils after freeze-thaw cycles without external water supply. For the open system, considerable studies have been carried out on the deformation characteristic properties (frost heave and thaw settlement) and water migration property of soils during freeze-thaw processes $[16,17]$. Eigenbrod [18] investigated the volume changes of soft fine-grained soils exposed to open-system freeze-thaw cycles and found that the volume remained constant after about 6 freeze-thaw 
cycles. Wang et al. [19] observed that the moisture migration reached stability after 3 freeze-thaw cycles in the open system. For the strength properties of soils subjected to freeze-thaw cycles with water supply, Aldaood et al. [3] tested the unconfined compressive strength of limestabilized soil subjected to freeze-thaw cycles in the open system with water supplement during the course of melting. However, the moisture migration caused by low temperature in winter has dramatic influence on the engineering properties of the soil in seasonally frozen soil areas. Considering that when the groundwater level is shallow or the temperature drops at low rate, the outer water will migrate to the freezing zone and accumulate during the freezing process of soil which brings about the formation of massive ice lens. Therefore, it is necessary to study the variation of mechanical properties of soil after freeze-thaw cycles under the open system when there is water supply during freezing.

The influence of freeze-thaw cycles on physical and mechanical properties of soil is reflected on the variation of microstructure of the soil [20-22]. Therefore, it is inevitable to study the microstructure changes of soil in the investigation on mechanical properties of clay under freezethaw cycles. In recent years, scanning electron microscopy (SEM) has been widely applied in the research on soil structure changes. Gullà et al. [21] noted that the soil microstructure altered from aggregated and flocculated to aggregated and deflocculated after undergoing wettingdrying-freezing-thawing cycles. Aldaood et al. [3] examined the SEM images of lime-stabilized gypseous soil after freeze-thaw cycles and observed that the pores in the soil increased and the structure becomes coarser.

The purpose of this study is to compare the effect of freezethaw cycles on physical and mechanical properties of compacted clay without and with water supply. Freeze and thaw cycles tests in the closed system with constant moisture content and open water system with external water supply were conducted, and the deformations during freeze-thaw process and moisture content after freeze-thaw cycles of samples were measured. Further, the unconsolidated undrained triaxial compression tests on specimens subjected to freeze-thaw cycles were carried out, and typical specimens of the closed and open system were selected for SEM tests, respectively.

\section{Materials and Methods}

2.1. Materials and Sample Preparation. In this paper, clayey soil taken from the levee of Songhua River basin in Northeast China was used as the object of this study. The basic physical parameters of the soil are shown in Table 1. According to the plastic index of the soil, the soil was defined as low liquid limit clay (CL) referring to the Specification of Soil Test (SL237-1999). To produce the remolded specimens with the initial moisture content of $20.2 \%$ and the initial dry density of $1.57 \mathrm{~g} / \mathrm{cm}^{3}$, the soil sample was air-dried, crushed, and then was sieved using a standard $2 \mathrm{~mm}$ sieve to abandon particles larger than $2 \mathrm{~mm}$ in diameter. According to the moisture content required, quantitative distilled water was mixed into the soil sample. Then, the soil sample was placed in a closed container for $24 \mathrm{~h}$ to ensure the uniformity of
TABLE 1: Basic physical parameters of the soil sample.

\begin{tabular}{lc}
\hline Physical index & Data \\
\hline Specific gravity & 2.71 \\
Maximum dry density $\left(\mathrm{g} / \mathrm{cm}^{3}\right)$ & 1.65 \\
Optimum moisture content $(\%)$ & 20.2 \\
Liquid limit $(\%)$ & 38.4 \\
Plastic limit (\%) & 23.5 \\
Plastic index & 14.9 \\
Grain size distribution $(\%)$ & \\
$>0.05 \mathrm{~mm}$ & 4.2 \\
$0.005-0.05 \mathrm{~mm}$ & 61.4 \\
$<0.005 \mathrm{~mm}$ & 34.4 \\
\hline
\end{tabular}

temperature and humidity in the soil. After that, the moisture content of soil sample was measured, and the error of moisture content was controlled within $0.5 \%$. The weighed soil sample was put into a specimen making device in five layers and compacted into a cylinder with $38 \mathrm{~mm}$ in diameter and $76 \mathrm{~mm}$ in height. Then, the specimens were covered with plastic films for using in the freeze-thaw test. For the freezethaw cycle test of the closed system, the specimen was completely wrapped in plastic film; for the open system, the top and side surfaces were sealed with plastic film while the bottom surface was exposed, as shown in Figure 1.

2.2. Experimental Device. Both closed-system and opensystem freeze-thaw tests were conducted by a selfdeveloped one-dimensional freeze-thaw setup in which 4 specimens can be placed at one time, shown in Figure 2(a). The details of the freeze-thaw equipment for one specimen are shown schematically in Figure 2(b). The specimen was installed in the nylon cylinder which was wrapped by rubber and plastic foam board on the outer wall to isolate heat exchange. In order to reduce the side friction between the specimen and cylinder, the inner wall of the cylinder was coated with a thin layer of Vaseline. The specimen was frozen and thawed from the top to the bottom by adjusting the temperature (the range of temperature is from $-40^{\circ} \mathrm{C}$ to $40^{\circ} \mathrm{C}$ ) of the circulating alcohol in the steel container at the top of the specimens. Meanwhile, the alcohol in the steel container at the bottom of the sample was kept at a constant temperature of about $1^{\circ} \mathrm{C}$, ensuring that the water in the Mariotte bottle can transfer to the soil through the bottom of the specimen during the freezing process without being frozen. The water level in the Mariotte bottle was at the same horizontal level as the base of the sample so that the water could be supplied without pressure. But, during the thawing process and closed-system test, the water switch was closed and there was no water replenishing. The frost heave and thaw settlement of the specimen was monitored constantly by the displacement sensor during the freeze-thaw test. The 4 freeze-thaw apparatuses were integrated together and placed into an environmental chamber, as shown in Figure 2(a), and the temperature of the environmental chamber was maintained at $1^{\circ} \mathrm{C}-2^{\circ} \mathrm{C}$.

2.3. Experimental Schemes. According to the average temperature of the coldest season and the hottest season of 


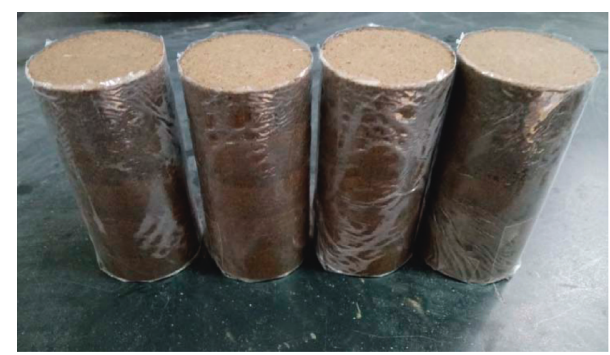

FIgURE 1: Wrapped specimens for the open system.

Harbin City in the Songhua River basin, the freezing temperature of this test was set to $-30^{\circ} \mathrm{C}$ and the melting temperature was set to $30^{\circ} \mathrm{C}$. The temperature change at different heights inside the specimen during one freeze-thaw cycle is shown in Figure 3. The results show that the temperatures at different positions of the specimen all reach below $0^{\circ} \mathrm{C}$ and gradually stabilize after freezing for $300 \mathrm{~min}$, and the internal temperatures all increase to above $0^{\circ} \mathrm{C}$ and then gradually stabilize after thawing for $120 \mathrm{~min}$. That is to say, the specimens are completely frozen after freezing for more than 5 hours at $-30^{\circ} \mathrm{C}$ and completely melted after thawing for more than 2 hours at $30^{\circ} \mathrm{C}$. In addition, to facilitate the experimental operation, the specimens were frozen unidirectionally at $-30^{\circ} \mathrm{C}$ for 8 hours and thawed at $30^{\circ} \mathrm{C}$ for 4 hours. The numbers of freeze-thaw cycles for the closed system and open system were both set to $0,1,3,5$, and 7 times. The sample was weighed before and after each test. After each freeze-thaw test, one of the samples was sliced into $1.5 \mathrm{~cm}$ pieces to test the moisture content of each slice; meanwhile, the SEM test was conducted. The other 3 samples were subjected to unconsolidated and undrained triaxial compression. The strain rate of the three axial compression test was $0.5 \% / \mathrm{min}$, and the confining pressures were 50,100 , and $150 \mathrm{kPa}$, respectively.

\section{Results and Discussion}

3.1. Effect of Freeze-Thaw Cycles on the Deformation and Moisture Content of Soil. The deformations of specimens in the closed system and open system during freeze-thaw cycles are shown in Figure 4. It is obvious that, under the two test conditions, the deformations of the specimens change periodically under the influence of temperature. For the open system, frost heave occurs at low temperatures and thaw settlement occurs at high temperatures. On the contrary, for the closed systems, frost shrinkage [23, 24] occurs at low temperatures and thaw expansion $[10,24]$ occurs at high temperatures. The stable deformations of the specimens after freeze-thaw cycles vary with freeze-thaw times are presented in Figure 5. It can be seen that the deformation of the sample in the open system increases with the increase of freeze-thaw cycles and gradually stabilizes, while the deformation of the sample in the closed system changes little. The final deformation of the former after 7 freeze-thaw cycles is close to $3 \mathrm{~mm}$ and about 6 times as large as that of the latter $(0.5 \mathrm{~mm})$.

In order to better characterize the effect of freeze-thaw cycles on soil deformation, the net deformation rate, $\eta_{\mathrm{FT}}$, is examined. This variable is defined as the proportion of deformation after thawing over the initial height of sample:

$$
\eta_{\mathrm{FT}}=\frac{\Delta H}{H_{0}},
$$

where $\eta_{\mathrm{FT}}$ is the net deformation rate (\%); $\Delta H$ is the deformation after thawing $(\mathrm{mm})$; and $H_{0}$ is the initial height of the sample $(\mathrm{mm})$.

The variation of the net deformation rate with the freezethaw cycles is also described in Figure 5. As shown in Figure 5, the maximum net deformation rate in the open system is nearly $40 \%$, while in the closed system, the value is only $6.5 \%$.

Figure 6 illustrates the variations of moisture content of specimens in the closed and open systems after freeze-thaw cycles. The specimens in the closed system are completely wrapped with plastic film, without external water supply; therefore, only the migration of a small amount of bound water in the soil will occur which results in very little changes in the moisture content along the height of the specimen (Figure 6(a)). In comparison with the closed system, the specimens in the open system are supplied with external water in the freezing process; accordingly, there is a significant change in the vertical distribution of moisture content, especially for the upper layers for specimens [16] where the increase of water content reaches $9 \%$ after 7 cycles. When the sample is frozen at $-30^{\circ} \mathrm{C}$ under the open system, the cooling speed is fast while the low permeability coefficient of the soil results in the slow water migration despite the large thermal gradient. Therefore, during the first freezing process, the external water has not yet migrated to the top of the sample; however, the sample has been completely frozen. Free water formed during melting can migrate slowly downward under the effect of gravity, but there is a freezing layer at the lower part of the sample, so water cannot completely diffuse downward in a short time. During the second freezing process, the water continued to move upward under the effect of thermal gradient but could not completely dissipate after melting. Therefore, with the increase of freeze-thaw cycles, the water gradually migrates to the top of the sample until the moisture content achieves a quasi-steady state after about 3 cycles. In addition, the water switch was closed during the thawing process, so it is not easy for the water to dissipate after the melting of frozen soil, which leads to the increase of the average moisture content of the specimen with more freeze-thaw cycles. And then, the average moisture content of the soil is almost stable after 3 freeze-thaw cycles (Figure 7) which is consistent with the result from Aldaood et al. [3]. The effect of freeze-thaw cycles and the variation of moisture content resulted in obvious changes in the appearance of the specimens, as shown in Figure 8. It indicates that the effect of freeze-thaw cycles with water supply on soil is more grievous than that without water supplement.

\subsection{Effect of Freeze-Thaw Cycles on the Strength Properties of Soil}

3.2.1. Failure Strength. The deviator stress-strain curves of soil samples subjected to $0,1,3,5$, and 7 freeze-thaw cycles in the closed system and open system are shown in Figures 9 


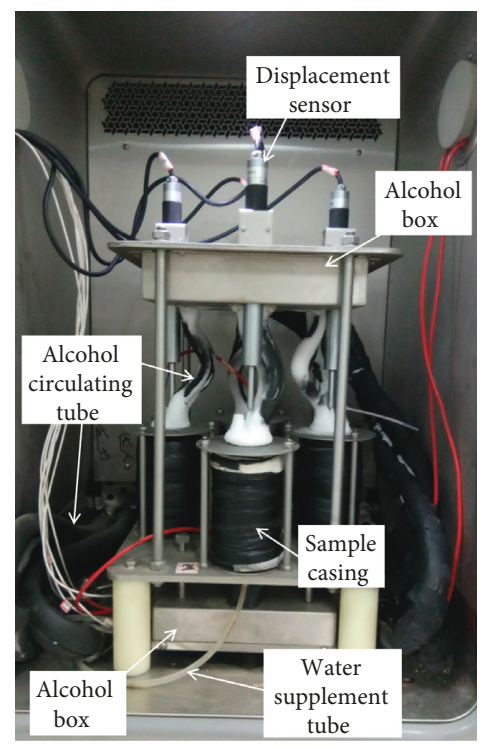

(a)

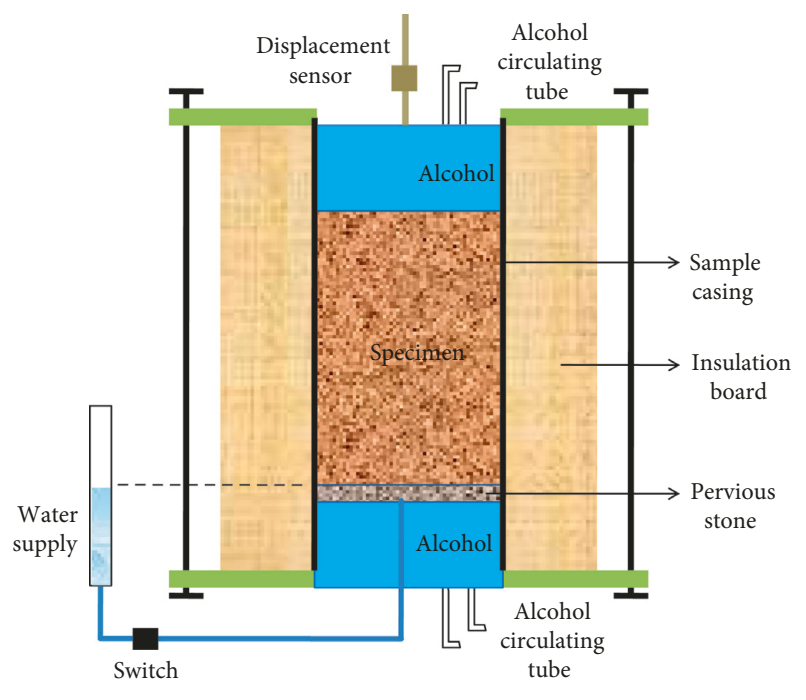

(b)

Figure 2: Apparatus for the freeze-thaw test. (a) Environmental chamber. (b) Schematic diagram.

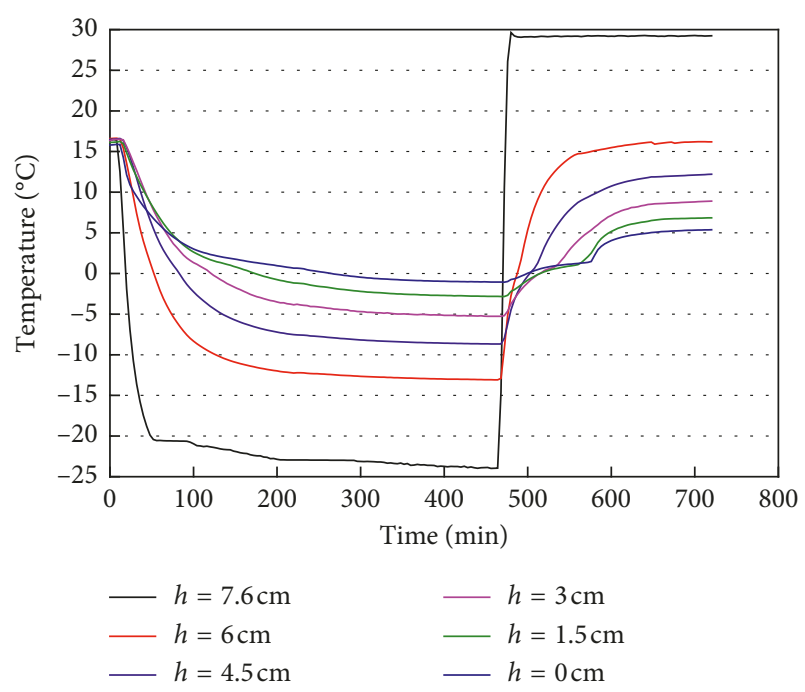

FIGURE 3: Variations of temperature inside the sample during one freeze-thaw cycle.

and 10 , respectively. According to these figures, the deviator stress-strain curves of different freeze-cycles all belong to strain-hardening type, whether water is supplied or not. This indicates that freeze-thaw cycles [11] and water supply has no significant effect on the type of the deviator stress-strain behavior. However, Liu et al. [15] concluded that the deviator stress-strain curves of silty sand transform from the type of weak strain softening to strain hardening with the increase of freeze-thaw cycles under the confining pressure of $100 \mathrm{kPa}$. On the contrary, Roustaei et al. [25] found that the deviator stress-strain curves of reinforced and unreinforced fine-grained soil convert from strain-hardening type to strain-softening type under the confining pressure of $30-90 \mathrm{kPa}$ after freeze-thaw cycles. These inconsistent results

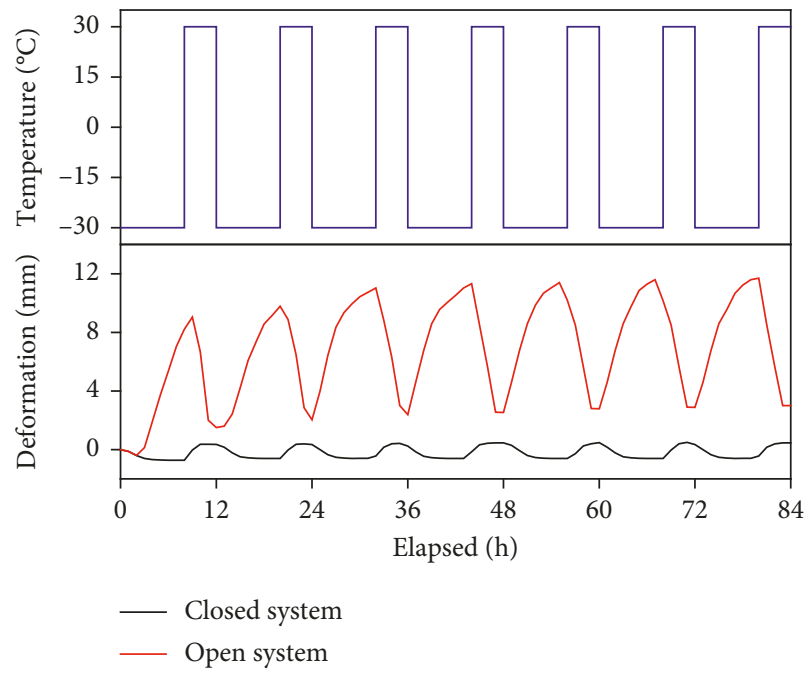

FIGURE 4: Variation of temperature and deformations of specimen with time.

are mainly due to the different soil types and experimental conditions. In addition, with the increase of freeze-thaw cycles, the deviator stress of the soil decreases. However, the deviator stress decrease of the soil is more remarkable in the open system than that in the closed system. For the open system, it is obvious that the deviator stress reduces mostly after the first freeze-thaw cycle, and the deviator stress-strain curves change little after 3 cycles which indicates that the mechanical properties of soil reach a stable state after 3 freeze-thaw cycles under the condition of water supply.

Taking the corresponding deviator stress at the strain of $15 \%$ as the failure strength [11], the influence of freeze-thaw cycles on the failure strength of soil under different confining pressures in the closed system and open system is shown in Figure 11. As seen, the failure strength of the soils 

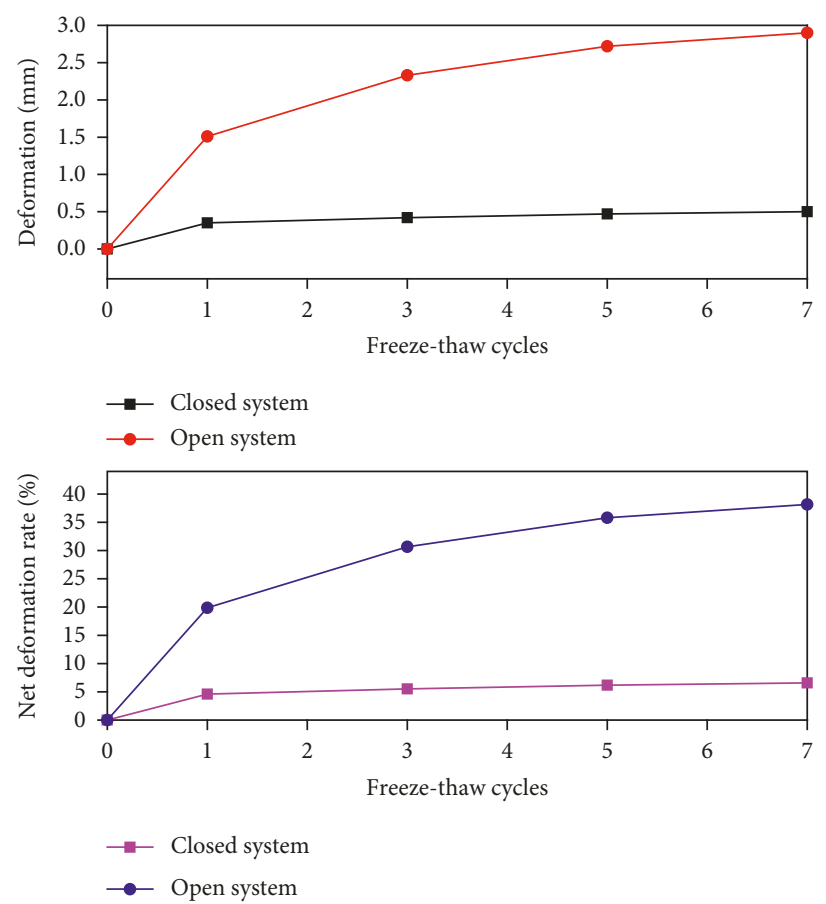

Figure 5: Variation of deformations and net deformation rate of specimens with the freeze-thaw cycles.

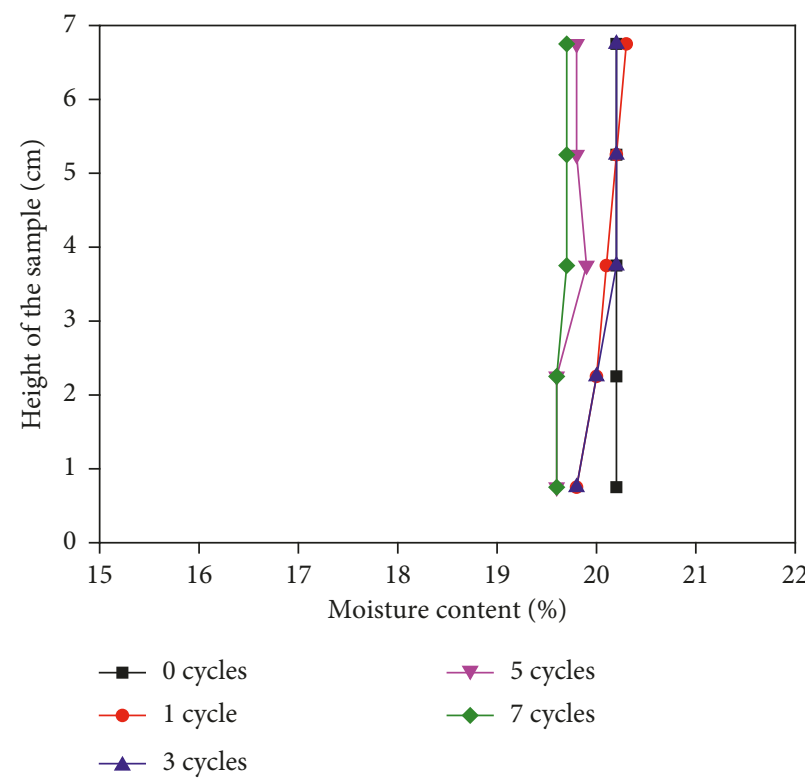

(a)

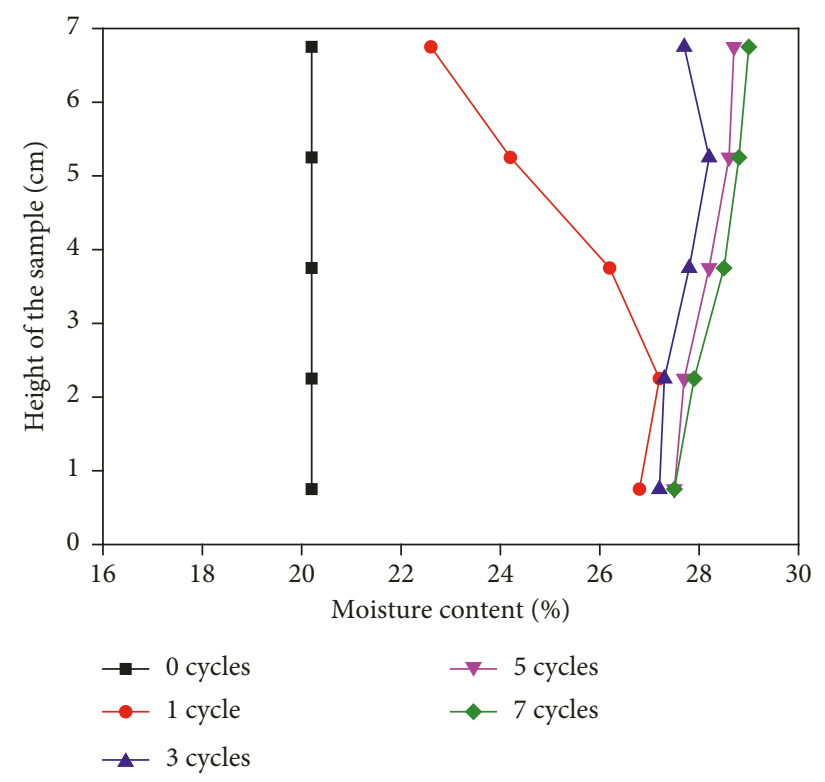

(b)

FIGURE 6: Moisture distribution by the height of the specimen after freeze-thaw cycles. (a) Closed system. (b) Open system.

decreases gradually with the increase of freeze-thaw cycles. For the closed system, the failure strength of the soil decreases by $42 \%$ after 7 freeze-thaw cycles, while the failure strength of the samples in the open system reduces by $84 \%-89 \%$ after the same cycles. Therefore, the deterioration effect of freeze-thaw cycles on soil strength is aggravated after water replenishment. It can be found that the maximum reduction of soil failure occurs after the first freeze-thaw cycle whether in the open system or the closed system $[11,25]$. It is apparent that the reduction of failure strength decreases with the increase of confining pressure. Moreover, for the sample in the open system, the failure strength has reached the stable state after 3 freeze-thaw cycles when the confining pressure is relatively low $(50 \mathrm{kPa})$, and when the confining pressure is high (100 and $150 \mathrm{kPa}$ ), the failure strength becomes relatively constant after 5 freeze-thaw cycles. However, in the closed system, the stability of mechanical properties of the soil can be 


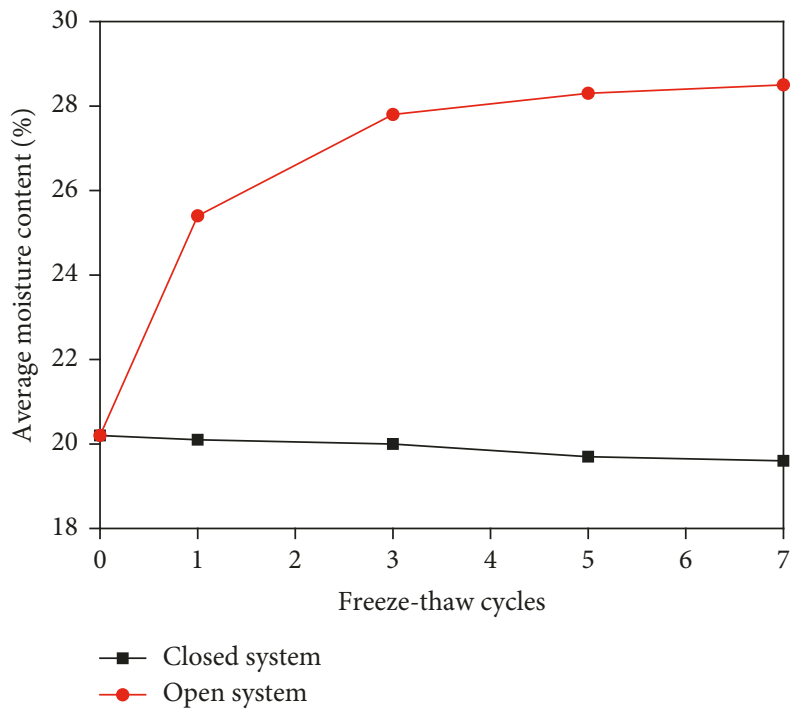

FIGURE 7: Variation of average moisture content with the freeze-thaw cycles.

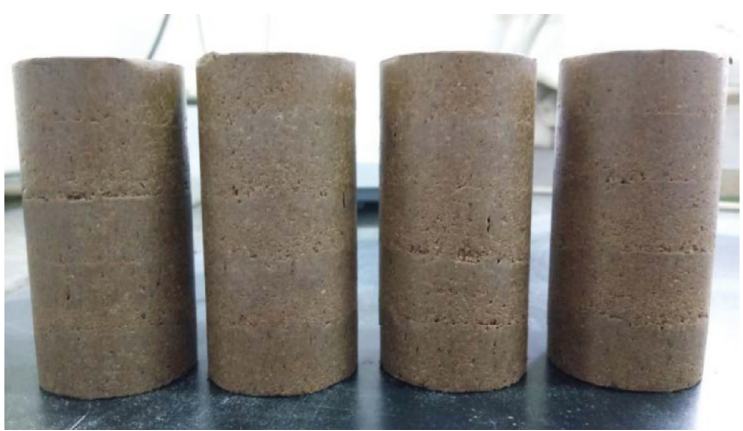

(a)

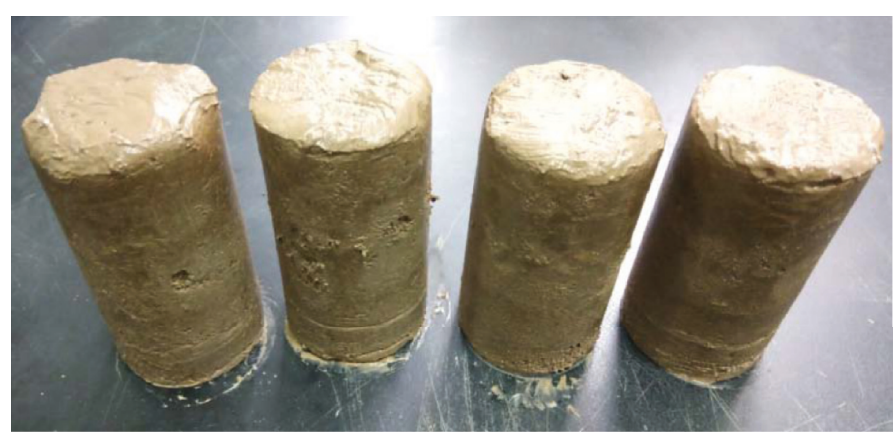

(b)

Figure 8: Specimens subsequent to 5 freeze-thaw cycles. (a) Closed system. (b) Open system.

achieved after 5-10 freeze-thaw cycles [26]. The constant state of failure strength is not clearly found in this test process because of the limited number of freeze-thaw cycles in the closed system. The aforementioned comparison shows that the supply of external water during the process of freeze-thaw cycles can accelerate the stability of the soil strength.

3.2.2. Elastic Modulus. The elastic modulus is defined as the ratio of the increment of deviator stress to the increment of axial strain when the axial strain is $1 \%[27,28]$, which can be expressed as

$$
E=\frac{\Delta \sigma}{\Delta \varepsilon}=\frac{\sigma_{1.0 \%}-\sigma_{0}}{\varepsilon_{1.0 \%}-\varepsilon_{0}},
$$

where $\Delta \sigma$ is the increment of deviator stress, $\Delta \varepsilon$ is the increment of axial strain, $\sigma_{1.0 \%}$ is the corresponding deviator stress at the axial strain of $1.0 \%$, and $\sigma_{0}$ and $\varepsilon_{0}$ are the initial stress and strain, respectively. The variations of elastic modulus with freeze-thaw cycles under different confining pressures in the closed system and open system are shown in
Figure 12. By comparison, it is obvious that the elastic modulus of the two test conditions both decrease sharply after the first freeze-thaw cycle and then remain constant gradually. The decreasing amplitude of samples in the closed system is $55 \% \sim 61 \%$, while for the samples in the open system, the reduction is up to $89 \%$ $95 \%$ when the elastic modulus comes to steady state. By comparative analyses, it can be seen that soil mechanical parameters such as failure strength (Figure 11(b)), elastic modulus (Figure 12(b)), average moisture content (Figure 7), and deformation (Figure 5) all change significantly in the early stage of freezethaw cycles and then gradually stabilize with the increase of freeze-thaw cycles. However, this phenomenon is not obvious in the closed system (Figures 5, 7, 11(a) and 12(a)). This demonstrates that external water replenishment during the freezing process aggravates the soil frost heave, resulting in the extreme deterioration of the mechanical strength of the soil.

3.2.3. Cohesion and Angle of Internal Friction. According to the failure strength of soils under the confining pressures of 


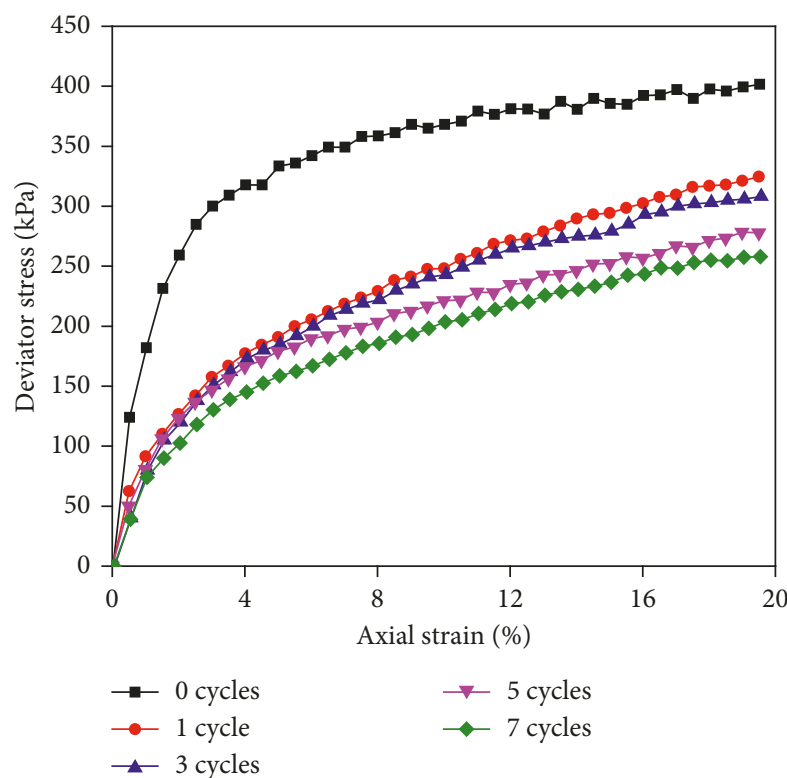

(a)

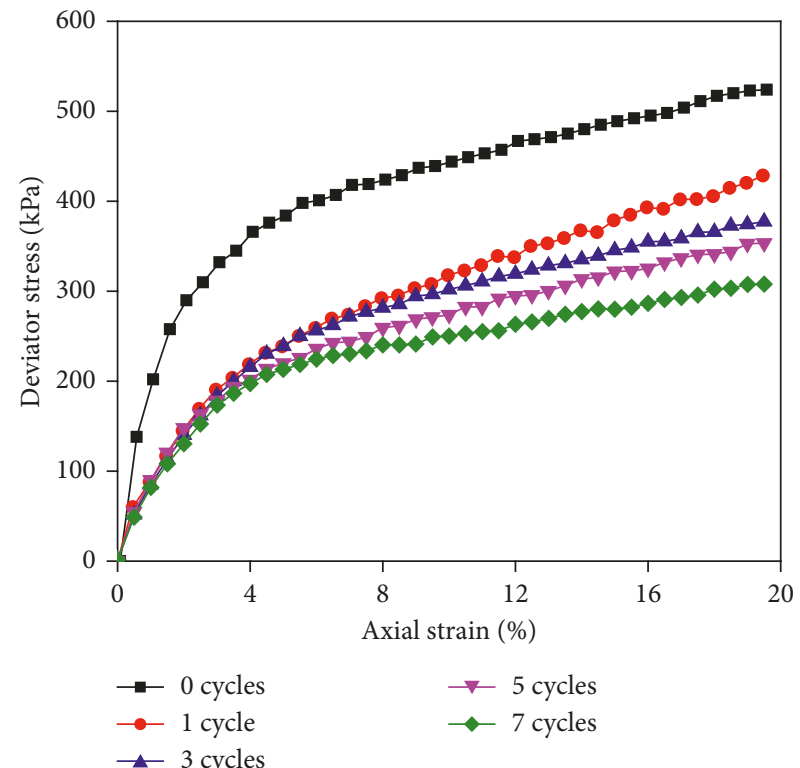

(b)

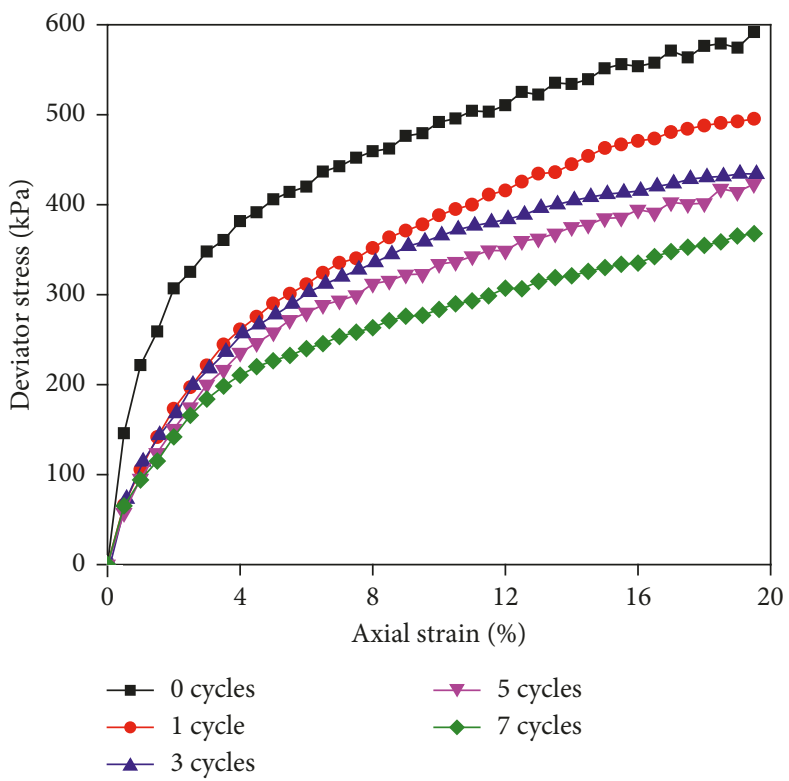

(c)

Figure 9: Deviator stress-strain curve in the closed system. (a) $\sigma_{3}=50 \mathrm{kpa}$. (b) $\sigma_{3}=100 \mathrm{kpa}$. (c) $\sigma_{3}=150 \mathrm{kpa}$.

50, 100 , and $150 \mathrm{kPa}$, the Mohr semicircles and the shear strength envelopes of the specimens were plotted to obtain the cohesion and internal friction angle. The variations of cohesion and angle of internal friction of the soil with freezethaw cycles under closed and open systems are shown in Figures 13 and 14, respectively. As can be observed from Figure 13, the cohesion of soils in closed and open systems both decrease gradually with the increase of freeze-thaw cycles and then gradually stabilize, which is in agreement with the results of remolded soils from Xu et al. [12]. Similar to the failure strength of soil, the cohesion decreases most after the first freeze-thaw cycle. The cohesion of the soil in the closed system decreases by $21 \%$ after 7 freeze-thaw cycles, while the cohesion of the soil in the open system reduces by $89 \%$ after the same cycles. This significant gap suggests that the external water supply forms a large number of segregated ice in the soil voids during the freezing process resulting in the increases of number and space of the pores between soil particles after the frozen soil melting. Besides, the increased moisture after freeze-thaw cycles also plays a crucial role in softening the soil, which leads to the further reduction of cohesion.

As can be noticed from Figure 14, the angle of internal friction of soils in the closed system decreases almost linearly with the increase of freeze-thaw cycles and this phenomenon verifies the variation of friction angle in the previous 7 


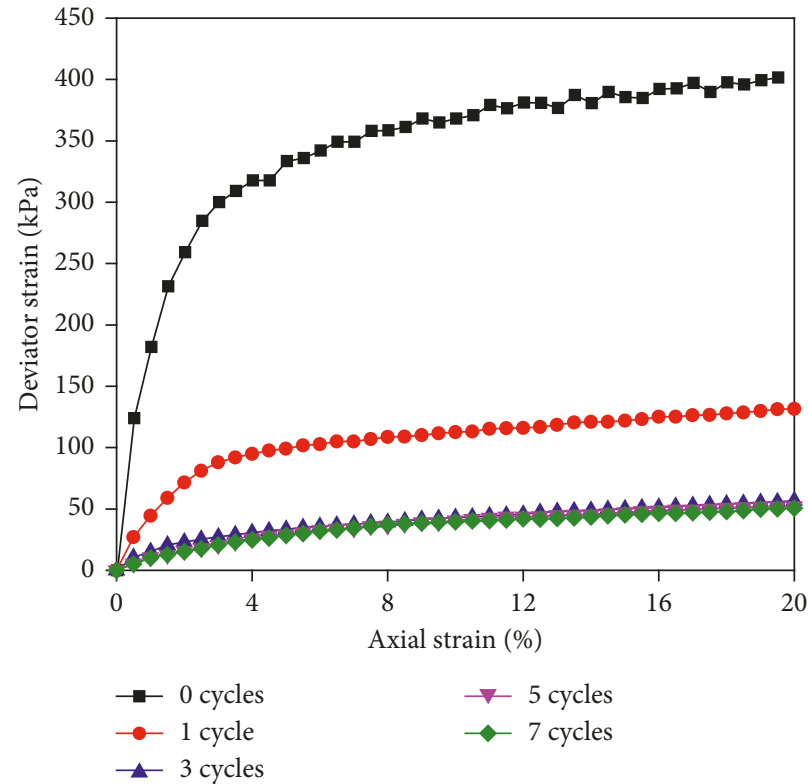

(a)

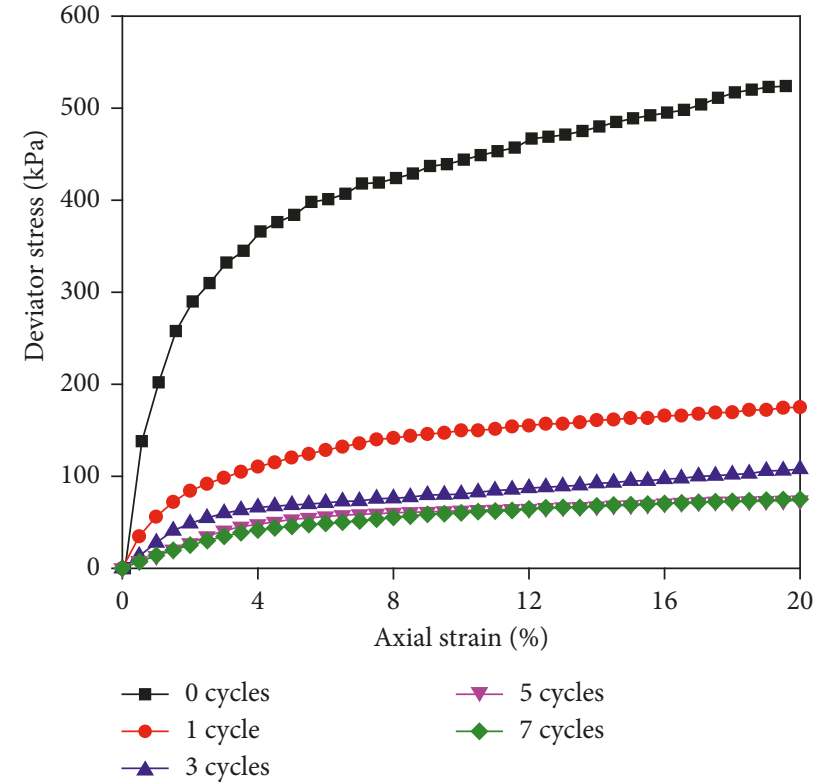

(b)

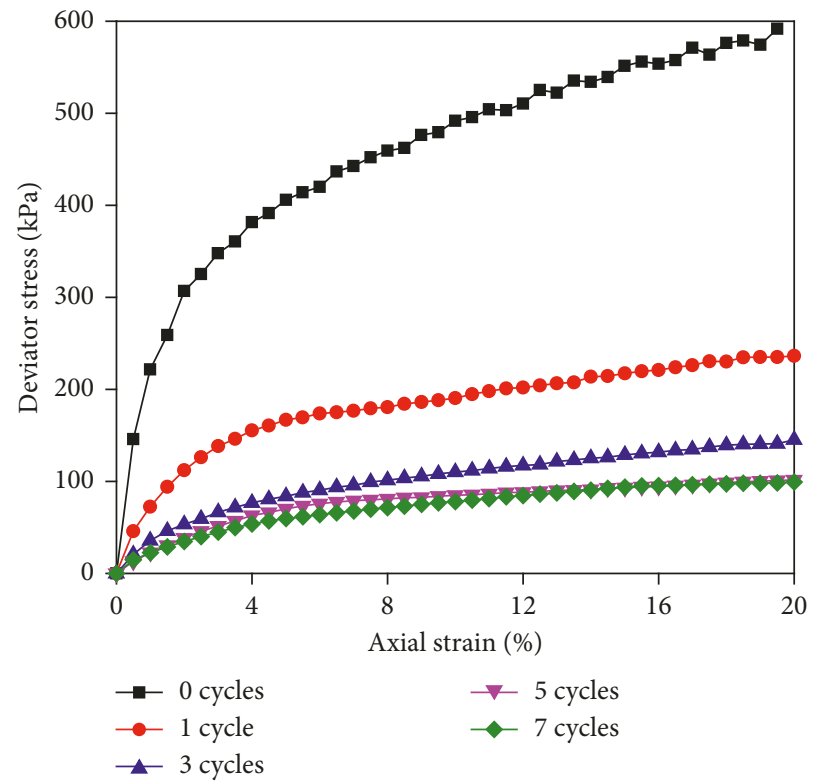

(c)

Figure 10: Deviator stress-strain curve in the open system. (a) $\sigma_{3}=50 \mathrm{kpa}$. (b) $\sigma_{3}=100 \mathrm{kpa}$. (c) $\sigma_{3}=150 \mathrm{kpa}$.

freeze-thaw cycles from the test result of Liu et al. [15]. In contrast, the internal friction angle of soils under the open system shows a stable trend after 5 freeze-thaw cycles and the value is just half of that in the closed system.

3.3. Change of Soil Microstructure. The discussion on soil microstructure is mainly concentrated on the changes of particle morphology and pore size [12]. The SEM pictures in the magnification of 800 for soils after different freeze-thaw cycles under closed and open systems are presented in Figure 15. The SEM image (Figure 15(a)) of the soil without freezing and thawing shows that the soil particles are tightly connected on the whole while other mono fine particles are scattered. After freeze-thaw cycles in the closed system, the amount of fine grain reduces and instead, the aggregation of particles appears. This indicates that the coagulation of small particles occurs, but the increase in the space between soil particles is not obvious (Figures 15(b)-15(d)). In contrast, not only the amount of large aggregation increases but voids between particles expand evidently under the open system (Figures 15(e)-15(g)). During the unidirectional freezing process, the external water migrates to the interior of the soil and a great quantity of segregated ice is formed in the frozen area accompanied by frost heave. Although the deformation of the soil recovers partially 


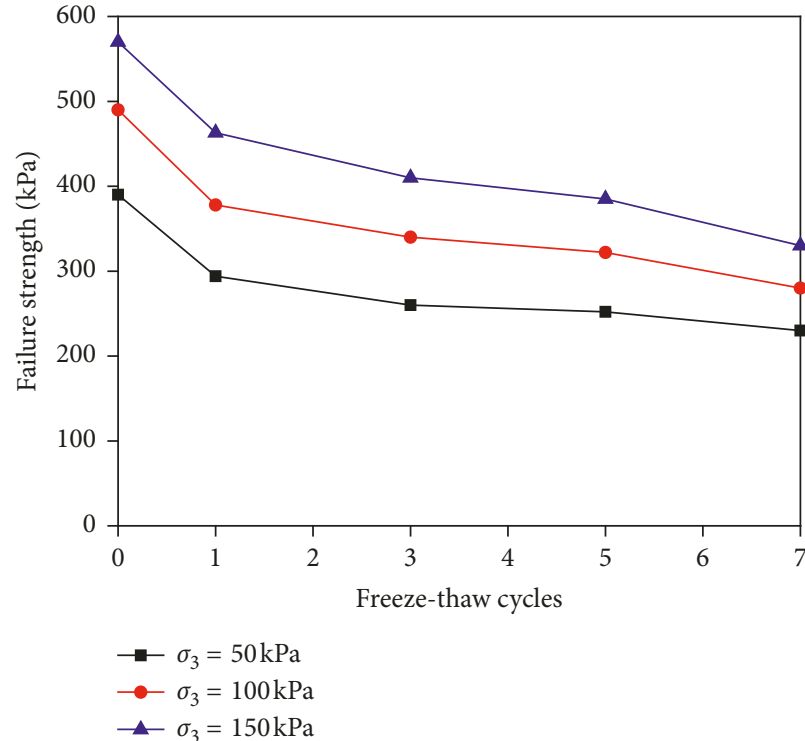

(a)

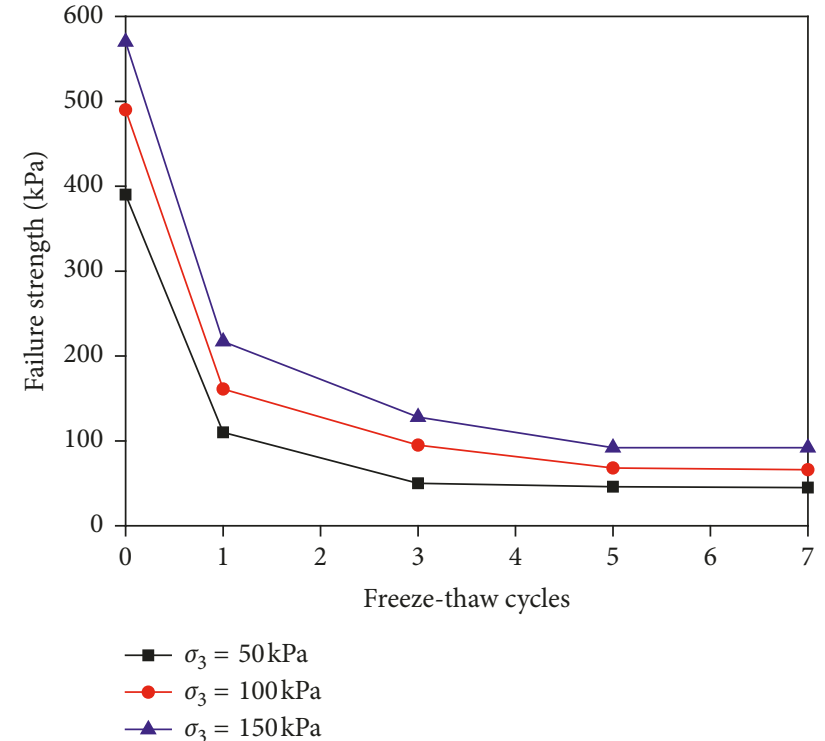

(b)

Figure 11: Variation of failure strength with the number of freeze-thaw cycles. (a) Closed system. (b) Open system.

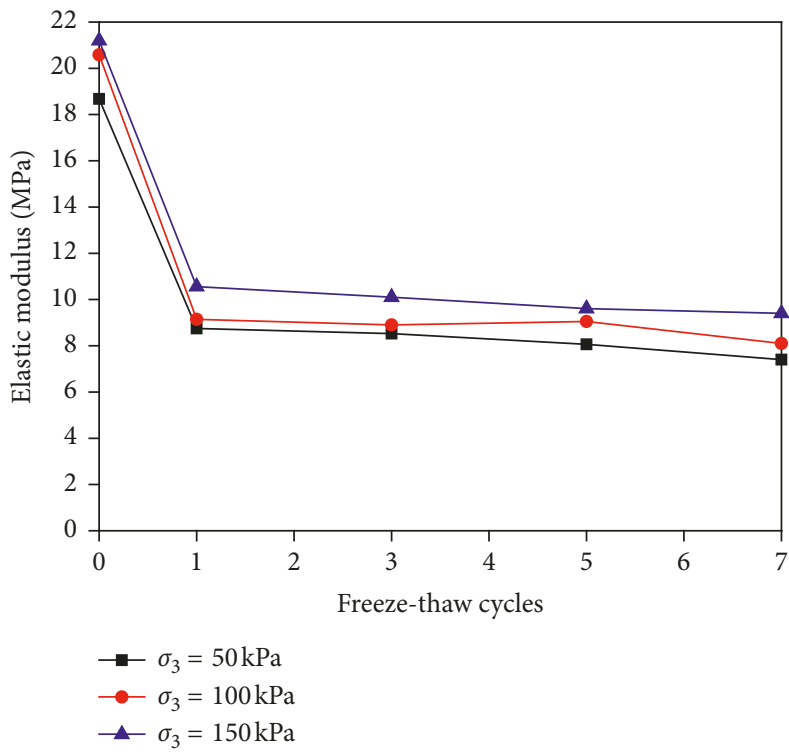

(a)

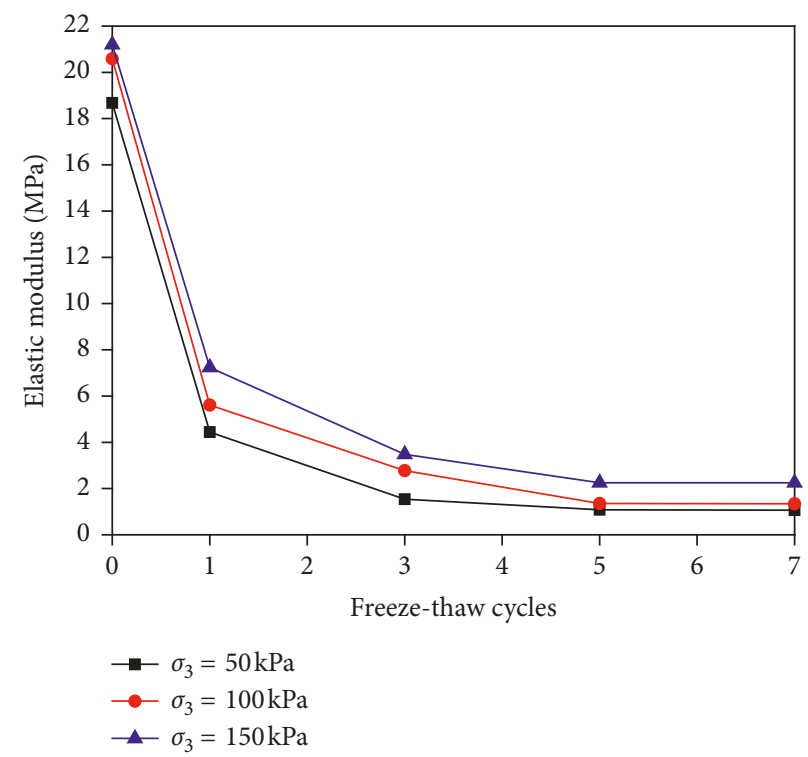

(b)

FIgURE 12: Variation of elastic modulus with the number of freeze-thaw cycles. (a) Closed system. (b) Open system.

during the thaw settlement, the distance between the soil particles increases in general and the formation of ice lenses results in the increase of large pores. With the progress of freeze-thaw cycles, the water transfers into the soil continuously; then, the size of the big pores increases further, thus developing a reticulate channel. Therefore, the effect of freeze-thaw cycles with water supply on soil structure is reflected as roughening and porous of microstructure in SEM images [3]. These microstructural transformations eventually trigger the reduction of mechanical properties of soil after freeze-thaw cycles.

\section{Discussion}

The freeze-thaw cycles have a significant deterioration effect on the engineering properties of soil. When the external water is supplemented during the freezing process, the water may migrate to the interior of the soil under the influence of cryogenic suction, i.e., temperature gradient, leading to further degradation in soil strength. Therefore, compared with the closed system, the freeze-thaw cycles in the open system have a greater impact on the engineering properties of soil. These effects are mainly manifested in two aspects. 


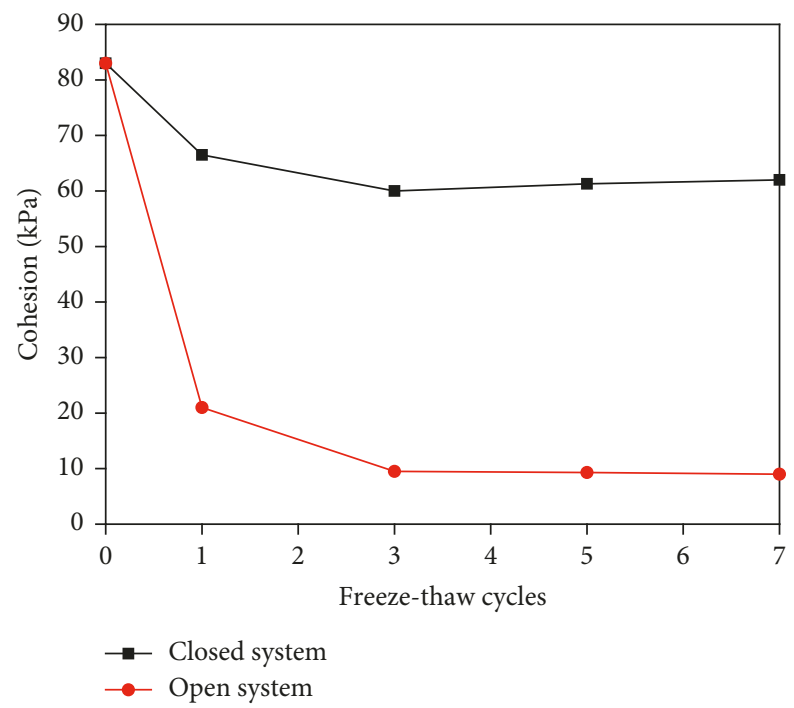

FIGURE 13: Variation of cohesion with the number of freeze-thaw cycles.

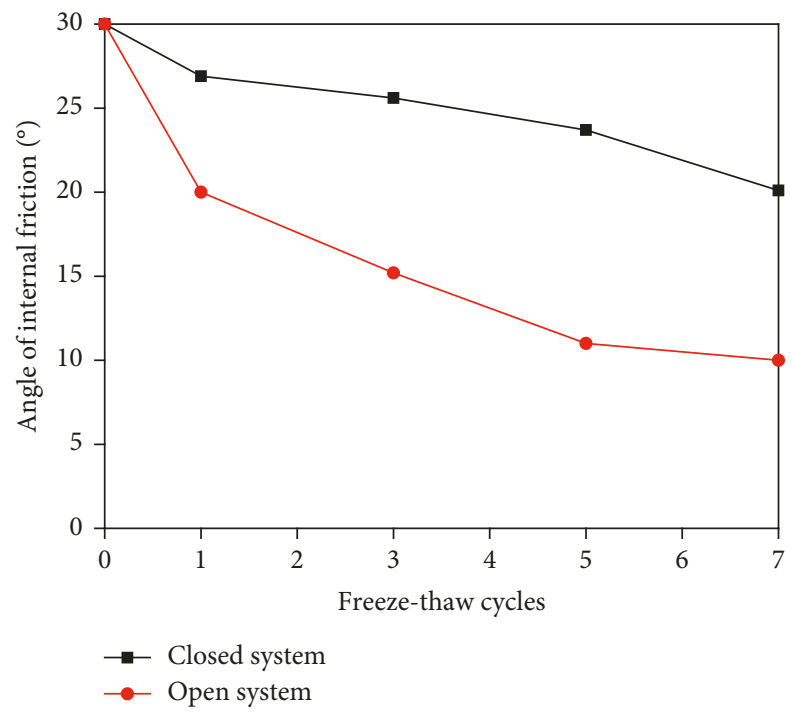

FIGURE 14: Variation of internal friction angle with the number of freeze-thaw cycles.

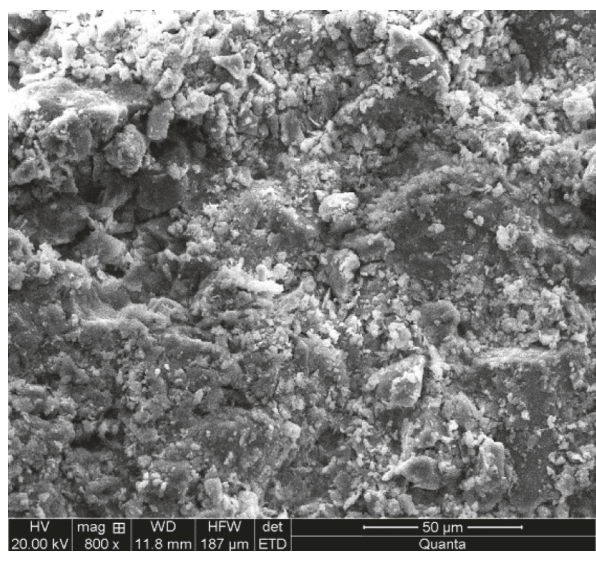

(a)

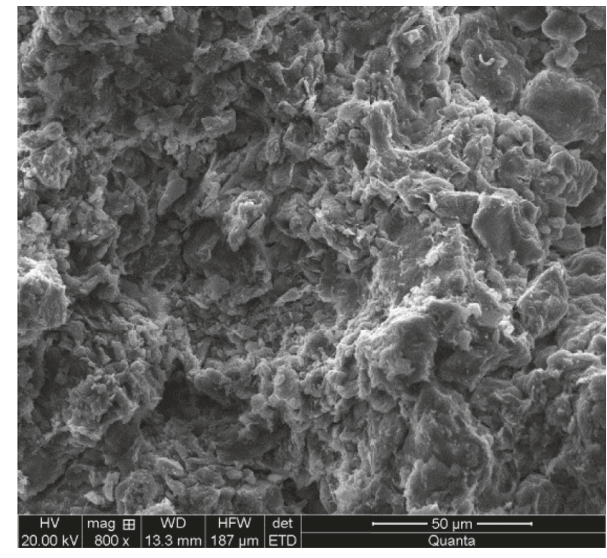

(b)

Figure 15: Continued. 


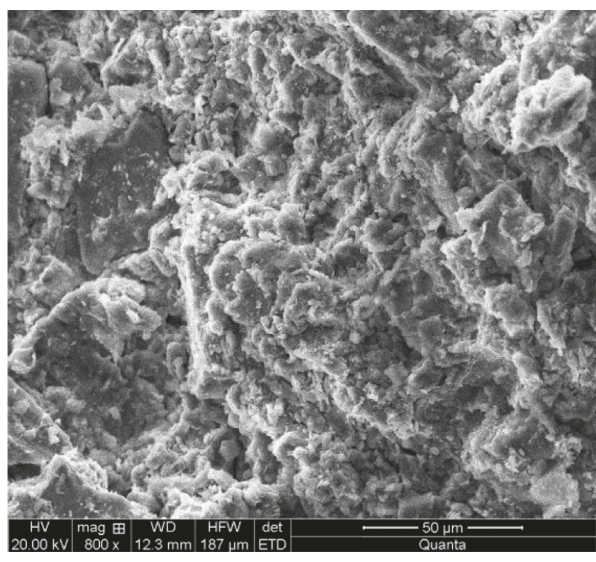

(c)

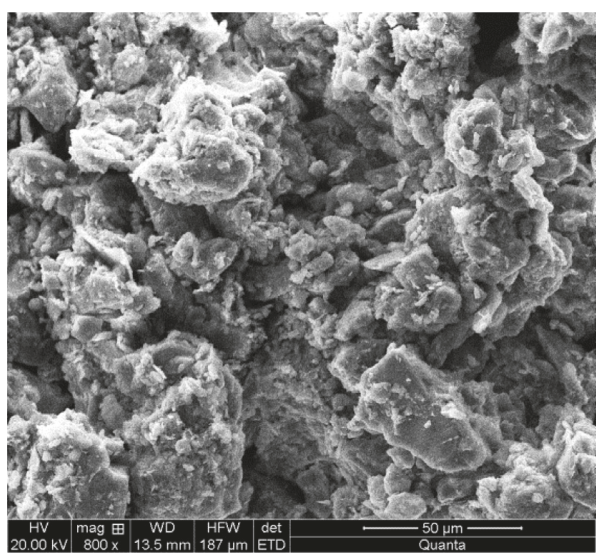

(e)

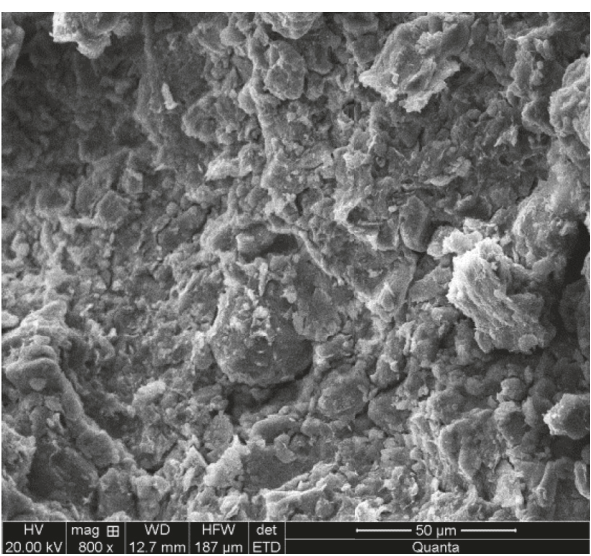

(d)

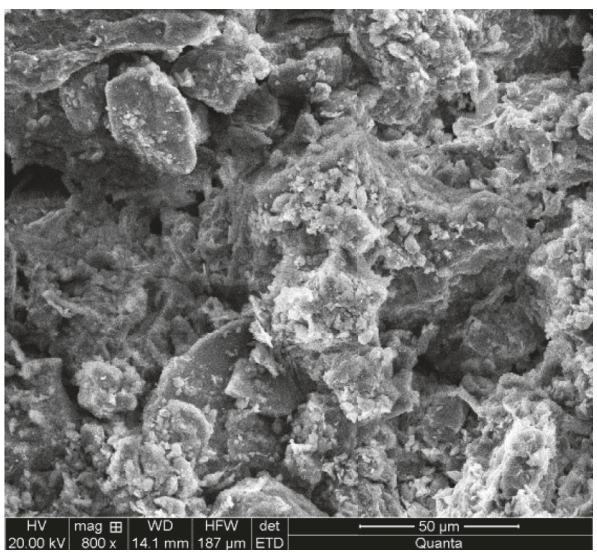

(f)

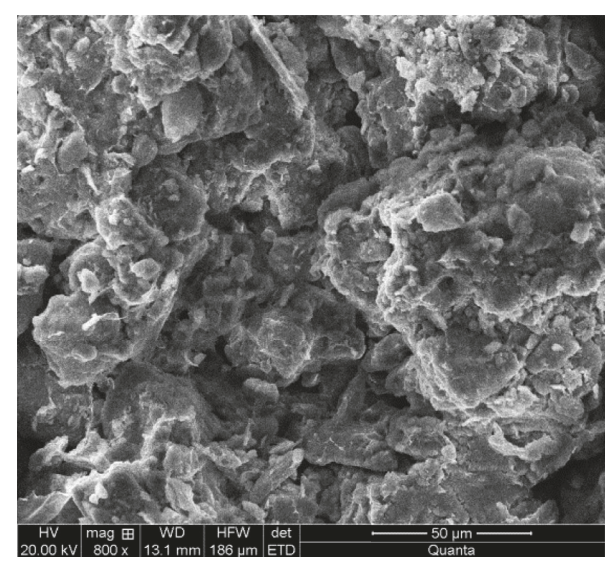

(g)

FiguRE 15: SEM pictures of the sample. (a) Without freezing-thawing cycle. (b) Closed system with 1 cycle. (c) Closed system with 3 cycles. (d) Closed system with 5 cycles. (e) Open system with 1 cycle. (f) Open system with 3 cycles. (g) Open system with 5 cycles.

On the one hand, the supplied water will accumulate at the freezing surface to form segregated ice during the freezing process. The accumulated water is not easy to dissipate after thawing and then continues to move to the upper part of the soil with the increase of freeze-thaw cycles, which leads to saturation of the upper part of the soil and causes potential subsidence hazards. On the other hand, due to the continuous water supply from the outside, the formation of a large number of thick segregated ice will lead to a substantial increase in the soil volume. The soil volume cannot be completely restored after melting, so the macrostructure of soil becomes loose and the compactness decreases, which causes the permeability increase and promotes the water migration. Meanwhile, with the increase of particle spacing and pore size, the internal channel in the microstructure is formed. Because of the above two factors, the mechanical indexes such as elastic modulus and shear strength of soils are more deteriorated by freeze-thaw cycles in open systems. 
Because of the above factors, freeze-thaw cycles under open system have a more serious deterioration effect on the elastic modulus and shear strength of soil.

In this paper, the physical and mechanical properties of soil subjected to freeze-thaw cycles under closed and open systems are compared and preliminarily explored. However, the influence of soil structure damage and moisture increase on the deterioration of soil engineering has not been distinguished for the case under the open system. This subject needs special research, which is also a direction of follow-up work.

\section{Conclusion}

The unconsolidated undrained triaxial compression tests and SEM tests were carried out on compacted clay subjected to freeze-thaw cycles in a closed system and an open system, respectively. The deformation, moisture content, mechanical properties (failure strength, elastic modulus, and shear strength parameters), and microstructure were contrastively analyzed to further manifest the effect of freeze-thaw cycles with water supply during the freezing process. The primary conclusions can be drawn:

(1) In the open system, the average moisture content of the sample comes to stable state after 3 freeze-thaw cycles. The increase of moisture content in the upper part of the sample is larger than that in the lower part, and the increase in magnitude reaches $9 \%$ in the top of the specimen after 7 cycles. However, moisture content of the sample in the closed system changes little.

(2) For the closed system, the failure strength of the sample decreases by $42 \%$ after 7 freeze-thaw cycles, while in the open system, it reduces by $84 \%-89 \%$. The decreasing amplitude of elastic modulus in the closed system is $55 \% \sim 61 \%$, while in the open system, the reduction is up to $89 \%$ 95\% when the elastic modulus comes to steady state. Compared with the closed state, the reduction of soil cohesion increases by 3 times after water supply. Therefore, the deterioration effect of freeze-thaw cycles on soil strength is aggravated after water replenishment.

(3) During the freezing process of the open system, the formation of ice lens induced by migrated water from the external can lead to the breaking of the soil structure and increase in moisture content after melting. Because of these reasons, the engineering properties of the soil in the open system are worse than those in the closed system.

(4) From the perspective of microstructure, the effect of freeze-thaw cycles on soil structure with water supply is reflected as roughening and porous of microstructure in SEM images.

\section{Data Availability}

The data used to support the findings of this study are available from the corresponding author upon request.

\section{Conflicts of Interest}

The authors declare that they have no conflicts of interest.

\section{Acknowledgments}

This work was supported by the Youth Innovation Promotion Association CAS, the Outstanding Youth Fund of Hubei Province (No. 2017CFA056), the Science and Technology Service Network Initiative (No. KFJ-STS-ZDTP037), and the National Natural Science Foundation of China (Nos. 41472286, 41472290, and 41672312).

\section{References}

[1] J.-H. Noh, S.-R. Lee, and H. Park, "Prediction of cryo-SWCC during freezing based on pore-size distribution," International Journal of Geomechanics, vol. 12, no. 4, pp. 428-438, 2012.

[2] R. L. Michalowski and M. Zhu, "Frost heave modelling using porosity rate function," International journal for Numerical and Analytical Methods in Geomechanics, vol. 30, no. 8, pp. 703-722, 2006.

[3] A. Aldaood, M. Bouasker, and M. Al-Mukhtar, "Impact of freeze-thaw cycles on mechanical behaviour of lime stabilized gypseous soils," Cold Regions Science and Technology, vol. 99, pp. 38-45, 2014.

[4] O. B. Andersland and B. Ladanyi, Frozen Ground Engineering, John Wiley \& Sons, Hoboken, NJ, USA, 2004.

[5] J. E. Aubert and M. Gasc-Barbier, "Hardening of clayey soil blocks during freezing and thawing cycles," Applied Clay Science, vol. 65-66, pp. 1-5, 2012.

[6] N. R. Morgenstern and J. F. Nixon, "One-dimensional consolidation of thawing soils," Canadian Geotechnical Journal, vol. 8, no. 4, pp. 558-565, 1971.

[7] G. Yesuf, I. Hoff, and J. Vaslestad, "Development of excess pore-water pressure in thawing process of frozen subgrade soils: based on analytical solutions and finite element method," in Proceedings of the 18th International Conference on Soil Mechanics and Geotechnical Engineering, Paris, France, September 2013.

[8] L. C. Wong and M. D. Haug, "Cyclical closed-system freezethaw permeability testing of soil liner and cover materials," Canadian Geotechnical Journal, vol. 28, no. 6, pp. 784-793, 1991.

[9] J. Graham and V. C. S. Au, "Effects of freeze-thaw and softening on a natural clay at low stresses," Canadian Geotechnical Journal, vol. 22, no. 1, pp. 69-78, 1985.

[10] J. Qi and W. Ma, "Influence of freezing-thawing on strength of over consolidated soils," Chinese Journal of Geotechnical Engineering, vol. 28, no. 12, pp. 2082-2086, 2006, in Chinese.

[11] D. Y. Wang, W. Ma, X. X. Chang, Z. Z. Sun, W. J. Feng, and J. W. Zhang, "Physico-mechanical properties changes of Qinghai-Tibet clay due to cyclic freezing and thawing," Chinese Journal of Rock Mechanics and Engineering, vol. 24, no. 23, pp. 4313-4319, 2005, in Chinese.

[12] J. Xu, J. Ren, Z. Wang, S. Wang, and J. Yuan, "Strength behaviors and meso-structural characters of loess after freezethaw," Cold Regions Science and Technology, vol. 148, pp. 104-120, 2018.

[13] S. Shoop, R. Affleck, R. Haehnel, and V. Janoo, "Mechanical behavior modeling of thaw-weakened soil," Cold Regions Science and Technology, vol. 52, no. 2, pp. 191-206, 2008. 
[14] W. Lee, N. C. Bohra, A. G. Altschaeffl, and T. D. White, "Resilient modulus of cohesive soils and the effect of freeze-thaw," Canadian Geotechnical Journal, vol. 32, no. 4, pp. 559-568, 1995.

[15] J. Liu, D. Chang, and Q. Yu, "Influence of freeze-thaw cycles on mechanical properties of a silty sand," Engineering Geology, vol. 210, pp. 23-32, 2016.

[16] G.-Y. Li, W. Ma, Y.-H. Mu, F. Wang, S.-Z. Fan, and Y.-H. Wu, "Effects of freeze-thaw cycle on engineering properties of loess used as road fills in seasonally frozen ground regions, North China," Journal of Mountain Science, vol. 14, no. 2, pp. 356-368, 2017.

[17] A. Sarsembayeva and P. E. F. Collins, "Evaluation of frost heave and moisture/chemical migration mechanisms in highway subsoil using a laboratory simulation method," Cold Regions Science and Technology, vol. 133, pp. 26-35, 2017.

[18] K. D. Eigenbrod, "Effects of cyclic freezing and thawing on volume changes and permeabilities of soft fine-gained soils," Canadian Geotechnical Journal, vol. 33, no. 4, pp. 529-537, 1996.

[19] T.-L. Wang, Y.-J. Liu, H. Yan, and L. Xu, “An experimental study on the mechanical properties of silty soils under repeated freeze-thaw cycles," Cold Regions Science and Technology, vol. 112, pp. 51-65, 2015.

[20] K. Czurda and M. Hohmann, "Freezing effect on shear strength of clayey soils," Applied Clay Science, vol. 12, no. 1-2, pp. 165-187, 1997.

[21] G. Gullà, M. C. Mandaglio, and N. Moraci, "Effect of weathering on the compressibility and shear strength of a natural clay," Canadian Geotechnical Journal, vol. 43, no. 6, pp. 618-625, 2006.

[22] M. Hohmann-Porebska, "Microfabric effects in frozen clays in relation to geotechnical parameters," Applied Clay Science, vol. 21, no. 1-2, pp. 77-87, 2002.

[23] M. A. Othman and C. H. Benson, "Effect of freeze-thaw on the hydraulic conductivity and morphology of compacted clay," Canadian Geotechnical Journal, vol. 30, no. 2, pp. 236-246, 1993.

[24] Y.-Q. Tang and J.-J. Yan, "Effect of freeze-thaw on hydraulic conductivity and microstructure of soft soil in Shanghai area," Environmental Earth Sciences, vol. 73, no. 11, pp. 7679-7690, 2015.

[25] M. Roustaei, A. Eslami, and M. Ghazavi, "Effects of freezethaw cycles on a fiber reinforced fine grained soil in relation to geotechnical parameters," Cold Regions Science and Technology, vol. 120, pp. 127-137, 2015.

[26] M. Ghazavi and M. Roustaie, "The influence of freeze-thaw cycles on the unconfined compressive strength of fiberreinforced clay," Cold Regions Science and Technology, vol. 61, no. 2-3, pp. 125-131, 2010.

[27] P. Kumar and S. P. Singh, "Fiber-reinforced fly ash subbases in rural roads," Journal of Transportation Engineering, vol. 134, no. 4, pp. 171-180, 2008.

[28] L. Li, W. Shao, Y. Li, and B. Cetin, "Effects of climatic factors on mechanical properties of cement and fiber reinforced clays," Geotechnical and Geological Engineering, vol. 33, no. 3, pp. 537-548, 2015. 


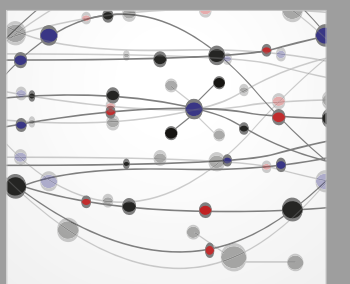

The Scientific World Journal
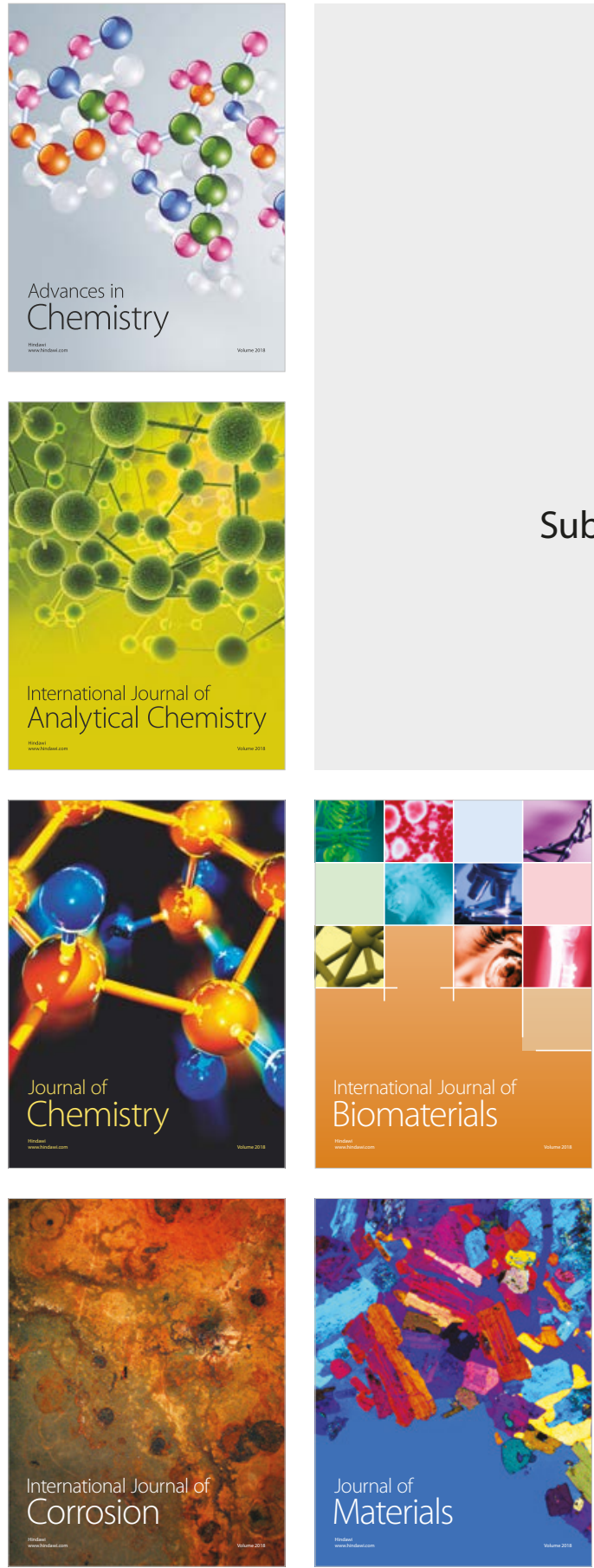

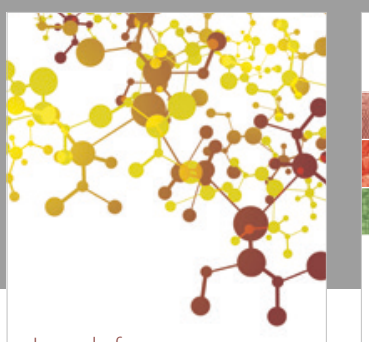

Journal of

Applied Chemistry
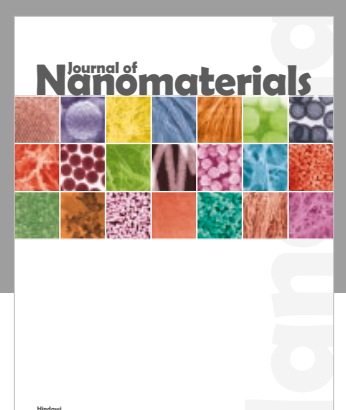

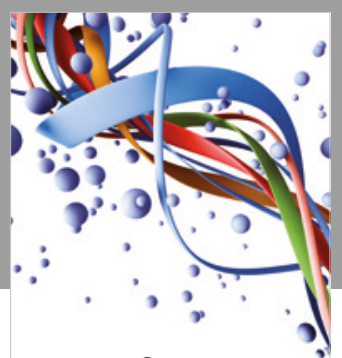

Scientifica

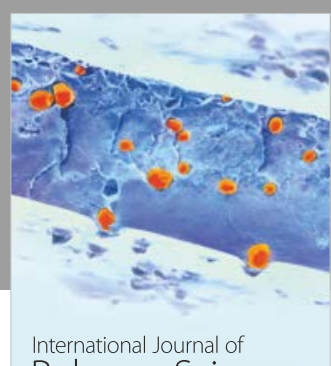

Polymer Science

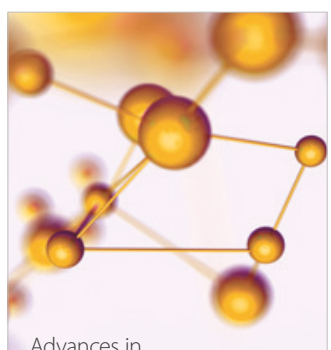

Physical Chemistry
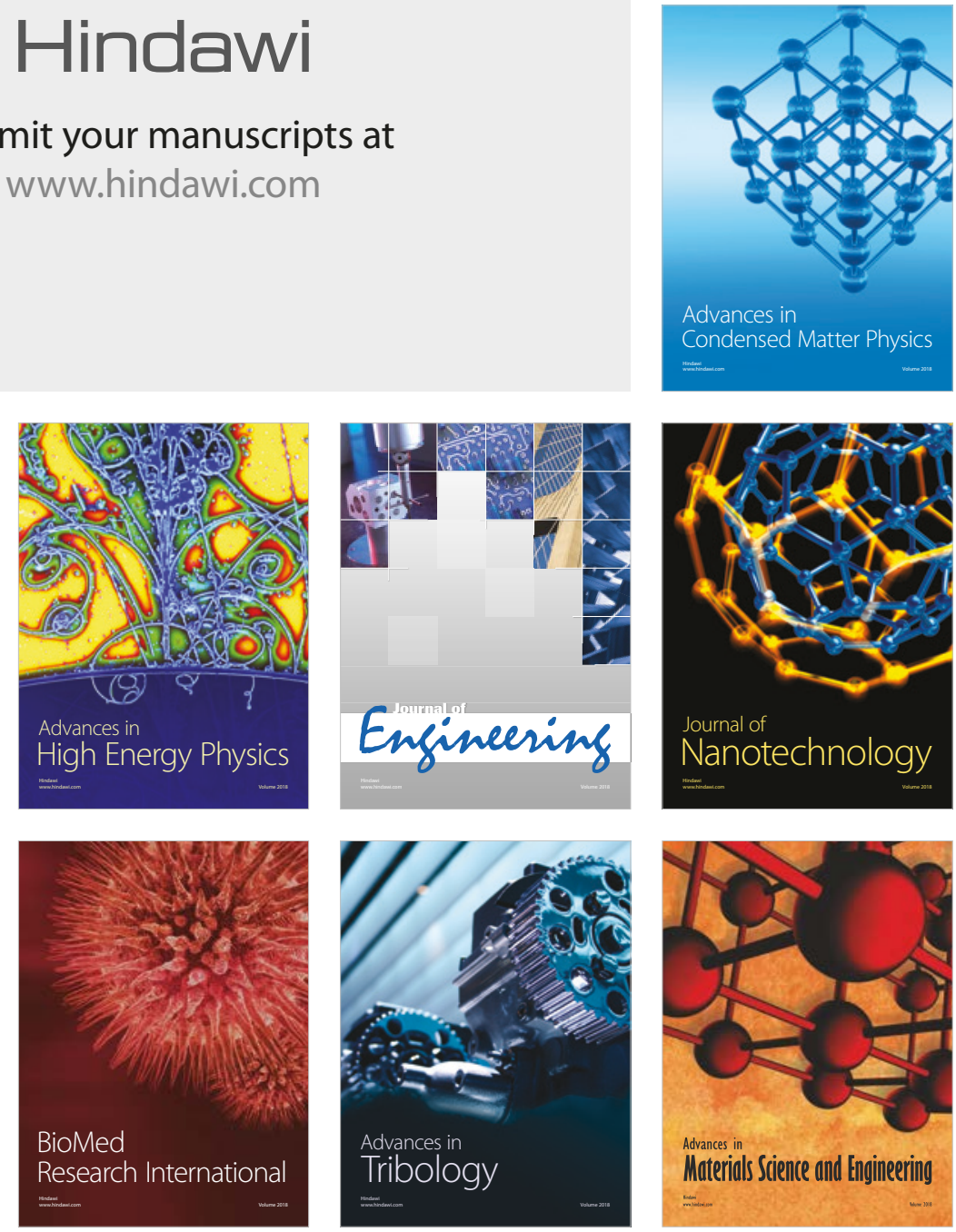